\title{
Association Between Maternal and Neonatal Serum Vitamin D Levels and the Incidence of Early-Onset Sepsis
}

\author{
Ali Naseh ${ }^{1,}$, Azade Shabani $^{2}$ and Hanieh Ghane ${ }^{2}$ \\ ${ }^{1}$ Taleghani Hospital, Shahid Beheshti University of Medical Sciences, Tehran, Iran \\ ${ }^{2}$ Shahid Beheshti University of Medical Sciences, Tehran, Iran \\ "Corresponding author: Taleghani Hospital, Shahid Beheshti University of Medical Sciences, Tehran, Iran. Email: alise1349@gmail.com \\ Received 2021 April 24; Revised 2021 October 31; Accepted 2021 November 24.
}

\begin{abstract}
Background: Early-onset neonatal sepsis (EOS) is a systemic infection that occurs within the first week of life.

Objectives: This study investigated the association of serum vitamin D levels in pregnant women and their neonates with the prevalence of EOS.

Methods: This case-control study was performed among 50 term/late pre-term neonates admitted to our NICU due to EOS, alongside 50 healthy neonates matched for gestational age range and sex. Maternal and neonatal serum vitamin D levels were measured. The criteria for diagnosing EOS included any/combination of: respiratory, cardiovascular, hemodynamic, neurological, gastrointestinal, body temperature, or metabolic signs. For sepsis cases, CBC, CRP, blood type, blood culture, chest X ray, and in some cases, and CSF analysis and culture were tested. Mothers' clinical history was collected.

Results: Each group included 30 (60\%) male and 20 (40\%) female neonates. Birth weight averages were $2772 \pm 667$ and $3215 \pm 349$ grams in the case and control groups, respectively $(\mathrm{P}<0.001)$. The mean serum vitamin D levels were $49.75 \pm 25.53$ and $56.41 \pm 18.17$ $\mathrm{nmol} / \mathrm{L}$ in the case and control groups, respectively. The control group mothers had a significantly higher vitamin D level (68.24 $\mathrm{nmol} / \mathrm{L}$ versus 55.01 in mothers of sepsis cases, $\mathrm{p}=0.005)$ and showed a correlation with the vitamin $\mathrm{D}$ levels of their neonates $(\mathrm{R}=$ $0.731, \mathrm{P}<0.001)$, while the data failed to show a correlation between vitamin $\mathrm{D}$ level in mothers and their neonates in the sepsis group $(\mathrm{R}=0.241, \mathrm{P}=0.115)$. C-section delivery was more prevalent among the sepsis cases $(\mathrm{P}<0.001)$.

Conclusions: Early-onset neonatal sepsis is associated with vitamin D deficiency in neonates and their mothers, low birth weight, and being delivered by C-section.
\end{abstract}

Keywords: Neonatal Early-Onset Sepsis, Neonatal Sepsis, 1,25-Dihydroxyvitamin D3, Vitamin D

\section{Background}

Vitamin D is a steroid hormone which can be produced in our skin under the ultraviolet radiation. Vitamin D plays an important role in the hemostasis of calcium and phosphorus and mineralization of bones $(1,2)$.

An active form of vitamin $D$ called 1,25dihydroxyvitamin D3 acts as an immune system moderator to stimulate the innate immune system $(3,4)$. Deficiency in vitamin D level during pregnancy has been reported between $18 \%$ and $84 \%(5,6)$, Several studies in adult patients have shown an association between the occurrence of sepsis and deficiency in vitamin D level (7). Also, some studies on neonates have shown an association between respiratory infections and sepsis and the presence of vitamin D deficiency (5).

Through a complex mechanism, vitamin D enhances immunity by inducing antimicrobial peptides in neu- trophils, epithelial cells, and macrophages (8). Vitamin D modulates systemic inflammatory response and locally controls pathogens by helping to inhibit or kill some bacterial strains. Direct invasion of pathogenic bacteria is prevented by vitamin D through enhancing the clearance of these infecting organisms at sites such as respiratory system (9).

However, information about the association between vitamin D deficiency and the occurrence of sepsis in neonates is still inconclusive. Neonatal sepsis indicates bacteremia and its related clinical signs and symptoms within the first month of birth and is an important cause of neonatal mortality. Since the immune system in neonates is not fully matured (10), they are susceptible to developing infections (11-13). Sepsis occurs among 1 to 8 neonates out of 1000 live births. Worldwide, one million neonates die annually due to sepsis (14). Neonatal sepsis is divided into two types based on its timing: early-onset sepsis (EOS) 
happens within the first seven days of birth, and late-onset sepsis (LOS) happens between the 8th day and the 28th day of birth. Early-onset sepsis is usually caused by microorganisms acquired from the mother. The risks for developing EOS include prematurity, low birth weight, prolonged labor, prenatal asphyxia, pre-mature rupture of amniotic membrane, foul smelling amniotic fluid, or the presence of meconium (11). Another study showed neonates born to mothers with low vitamin D levels and neonates with low cord vitamin D levels were at risk for neonatal sepsis (15).

Neonatal sepsis may leave long-term negative health effects for the child; thus, identifying the associated risk factors and implementing prevention measures may reduce the occurrence of sepsis and its side effects, utilization of NICUs and the associated costs, and separation of mothers and their neonates.

\section{Objectives}

Due to the role of vitamin D in strengthening the immune system and the high mortality rate among neonates who develop sepsis, this research aimed to evaluate the possible association between serum vitamin D levels in pregnant mothers and their neonates and the incidence of EOS. Also, the association between maternal and neonatal serum vitamin D levels was evaluated.

\section{Methods}

This prospective case-control observational study included 50 term or late pre-term neonates $(\geq 34-37<$ weeks) who were diagnosed with early-onset neonatal sepsis and were consecutively admitted to NICU in Taleghani Hospital, Tehran, Iran from July to December 2019. The control group included 50 healthy neonates matched for gestational age range ( $<37$ or $\geq 37$ week) and sex from our outpatient clinic. We matched neonates younger than 37 GA weeks in the case and control groups, and then we matched neonates with GA equal or more than 37 weeks from the case and control groups. The criteria for diagnosing EOS included (16) any or a combination of the following clinical signs: respiratory signs (distress, apnea, tachypnea, and hypoxemia), cardiovascular signs (tachycardia and bradycardia), hemodynamic signs (change in skin color, tissue hypoperfusion, and hypotension), neurological signs (irritability, lethargy, hypotonia, low activity, and convulsion), gastrointestinal system signs (poor feeding, abdominal distension (17), and not tolerating the feed), changes in body temperature (fever over 38 Celsius degrees or over 100.4 ${ }^{\mathrm{F}}$ and hypothermia lower than $36 \mathrm{Cel}-$ sius degrees or less than $96.8^{\mathrm{F}}$ ), or metabolic signs (aci- dosis or hyperglycemia). The following tests were performed for the neonates diagnosed with EOS: complete blood count, C-reactive protein, blood type, serum vitamin D level, and blood culture. Chest X ray, and in some cases, cerebrospinal fluid analysis and culture were examined. Serum vitamin D levels for the case and control groups were measured. Serum vitamin D level and clinical history for all the mothers were collected.

With the type 1 error of maximum 0.05 , the statistical power of $80 \%$, the difference of at least 10 units between the two groups, and the standard deviation of 15 units, the sample size calculated for each group was 35 neonates. The sample size in this study was 50 neonates with EOS and 50 healthy control neonates. After proving the normality of the distribution of the studied variables by KolmogorovSmirnov test, to examine the relationship between qualitative variables between the groups, Chi-square test or Fisher's exact test and for quantitative variables t-test for normally distributed data and Mann-Whitney test for nonnormally distributed data were used. Pearson test evaluated the correlation between serum vitamin D levels in mothers and their neonates. SPSS (IBM version 25) was used for statistical analysis. A P-value of less than 0.05 was considered statistically significant. Patient privacy and medical research ethics were observed.

\section{Results}

Demographics of 50 neonates diagnosed with EOS and 50 healthy neonates as control group are presented in Table 1 . Each group included 30 (60\%) boys and 20 (40\%) girls. The average birth weight were 2772 and 3215 grams for the sepsis and control groups, respectively, and Student's t-test showed that the control group had a higher birth weight compared to sepsis cases $(\mathrm{P}<0.001)$ as detailed in Table 1 . The mean gestational age for the sepsis cases was $36 \pm 2$ (range 34-40) weeks, and for the control group it was $38 \pm$ 1 (range 36-40) weeks $(\mathrm{P}<0.001)$.

Table 2 presents the data obtained from the complete blood count and C-reactive protein tests for the sepsis cases. The mean serum vitamin D level for sepsis cases was $49.75 \pm 25.53 \mathrm{nmol} / \mathrm{L}$ (range 20.47-157.25) (or $19.93 \pm$ $10.23 \mathrm{ng} / \mathrm{mL}$, range 8.2-63), and for the control group it was $56.41 \pm 18.17 \mathrm{nmol} / \mathrm{L}$ (range 13.73-89.86) (or 22.6 \pm 7.28 $\mathrm{ng} / \mathrm{mL}$, range 5.5-36). Compared to the sepsis cases, the control group had higher serum vitamin $\mathrm{D}$ levels $(\mathrm{P}=0.022)$. The list of neonates' chief complaints is presented in Table 2 and includes: respiratory symptoms such as grunting or tachypnea, feeding intolerance, mottling or hypoperfusion, and fever together with lethargy and feeding intolerance. In the sepsis group, blood culture for 45 (90\%) 


\begin{tabular}{|c|c|c|c|}
\hline Neonates & $\begin{array}{c}\text { Sepsis Cases }(\mathbf{n}= \\
50)\end{array}$ & $\operatorname{Control}(\mathbf{n}=\mathbf{5 0})$ & PValue \\
\hline Sex, No. (\%) & & & $>0.999^{\mathrm{a}}$ \\
\hline Male & $30(60)$ & $30(60)$ & \\
\hline Female & $20(40)$ & $20(40)$ & \\
\hline Birth Weight (gr) & & & $<0.001^{b, c}$ \\
\hline Mean \pm SD & $2772 \pm 667$ & $3215 \pm 349$ & \\
\hline Range & $1350-4900$ & $2300-3900$ & \\
\hline $\begin{array}{l}\text { Gestational Age } \\
\text { (week) }\end{array}$ & & & $<0.001^{\mathrm{b}, \mathrm{c}}$ \\
\hline Mean \pm SD & $36 \pm 2$ & $38 \pm 1$ & \\
\hline Range & $34-40$ & $36-40$ & \\
\hline
\end{tabular}

${ }^{a} \mathrm{P}$ value was calculated using Chi-Square and Fisher's Exact Tests.

${ }^{\mathrm{b}} \mathrm{P}$ value was calculated using T-test.

${ }^{c} \mathrm{P}$ value is less than 0.05 and shows statistical significance.

neonates was negative. Chest X-ray for 14 (28\%) of the sepsis cases showed opacity.

Table 3 presents the characteristics of mothers of the neonates in both groups. Serum vitamin D levels were lower in mothers of the neonates with sepsis compared to the control mothers $(55.01 \pm 22.11$ versus $68.24 \pm 21.22$ $\mathrm{nmol} / \mathrm{L}$, respectively; $\mathrm{P}=0.005)$. Also, there was a higher chance that mothers of the sepsis cases delivered through C-section ( $\mathrm{P}=0.001)$.

As Table 4 displays, evaluating the serum vitamin $\mathrm{D}$ levels in neonates with sepsis and their mothers failed to show any correlation between maternal and neonatal serum vitamin D levels $(R=0.241, P=0.115)$. However, for the control group, neonatal and maternal serum vitamin D levels were positively correlated, and neonates' serum vitamin D levels followed maternal serum vitamin D levels ( $R$ $=0.731, \mathrm{P}<0.001$ ).

\section{Discussion}

Our study showed that neonates experiencing EOS alongside their mothers had lower serum vitamin D levels compared to the control group. Another study has similarly reported that serum vitamin D level was lower in neonates with sepsis (18). Although the case-control study was designed for matched pairs within GA ranges, the sepsis group happened to have a bit lower gestational age, which may have resulted in lower birth weight compared to the control group. Despite the high importance of matching in case-control studies, this type of research bias may still happen in small sample sizes like ours, which may necessitate some compromise in the precision of matching criteria. For example, for GA we used a range rather than an exact number. Yet, in larger sample sizes, there is a higher chance of finding exact matching pairs for casecontrol studies.

However, unlike our results, an observational study showing similar results for vitamin D levels did not find any difference between neonates with sepsis and healthy control neonates in terms of birth weight (19). Also, contrary to a study by Say (20) who found no significant correlation between vitamin $D$ level in the cord blood and the risk of neonatal sepsis in premature neonates, other studies by Agraval et al. and Dhandai et al. have similarly reported lower serum vitamin D levels in neonates with sepsis although they had studied late-onset sepsis $(21,22)$. In our study, among neonates with sepsis, there was a higher chance of being delivered through C-section compared to the control group. A study showed no difference between neonates with sepsis and healthy control neonates regarding their mode of delivery (19). Similar to our study, Ozdemir and Cag and Dhandai et al. found lower levels of vitamin $\mathrm{D}$ in the serum of mothers of neonates who developed sepsis $(20,23)$.

Our study showed that the serum vitamin D level in mothers was positively associated with the serum vitamin D level in their healthy neonates. This finding was supported by a study by Cetinkaya et al (18).

Additionally, Dhandai et al. studying late-onset sepsis reported an association between serum vitamin D levels in mothers and their neonates even when the neonate developed sepsis. Yet, we only could find this association between healthy control neonates and their mothers. They also found that neonates' low serum vitamin D level was associated with a higher incidence of sepsis, and as a result, showed that maternal serum vitamin D level affected the incidence of sepsis (21). However, our findings failed to show any association between maternal and neonatal vitamin D levels among sepsis cases perhaps due to the limited sample size. Another reason may be that we evaluated maternal vitamin D levels of the sepsis cases during the last trimester of pregnancy and not necessarily in the last days of pregnancy or after delivery. Thus, perhaps some mothers might have taken vitamin D supplements.

Other studies have not considered these effects in their reports (21).

A study by Saboute et al. showed that higher levels of vitamin D in maternal serum reduced the incidence of neonatal sepsis (24). Although our data failed to show any association between serum vitamin D levels in maternal and neonatal samples, sepsis cases had lower levels of serum vitamin D similar to the above study. Also, Saboute's study showed a positive association between increased maternal age and higher prevalence of sepsis in neonates. Our data could not find these associations. Additionally, they 
Naseh A et al.

\begin{tabular}{|c|c|c|c|c|c|}
\hline \multirow[t]{2}{*}{ Neonates } & \multicolumn{2}{|c|}{ Sepsis Cases $(\mathbf{n}=\mathbf{5 0})$} & \multicolumn{2}{|c|}{ Controls $(\mathbf{n}=\mathbf{5 0})$} & \multirow[t]{2}{*}{ PValue } \\
\hline & Mean $\pm \mathbf{S D}$ & Range & Mean $\pm \mathbf{S D}$ & Range & \\
\hline Serum Vitamin D (nmol/L) & $49.75 \pm 25.53$ & 20.47-157.25 & $56.41 \pm 18.17$ & $13.73-89.86$ & $0.022^{\mathrm{b}}$ \\
\hline Hemoglobin $(\mathrm{mmol} / \mathrm{L})$ & $9.77 \pm 2.1$ & $6.7-19.86$ & & & \\
\hline White Blood Cell (per microliter) & $14778 \pm 6598$ & $5100-30000$ & & & \\
\hline Platelets (per microliter) & $227840 \pm 87779$ & $44000-571000$ & & & \\
\hline C-Reactive Protein (mg/L) & $17.2 \pm 5.1$ & 11-37 & & & \\
\hline \multicolumn{6}{|l|}{ Chief Complaint, No. (\%) } \\
\hline Respiratory (grunting, tachypnea) & $32(64)$ & & & & \\
\hline Feeding Intolerance & $8(16)$ & & & & \\
\hline Mottling, Hypoperfusion & $3(6)$ & & & & \\
\hline Fever, Lethargy, Feeding Intolerance & $7(14)$ & & & & \\
\hline \multicolumn{6}{|l|}{ Blood Culture, No. (\%) } \\
\hline Negative & $45(90)$ & & & & \\
\hline Positive & $5(10)$ & & & & \\
\hline \multicolumn{6}{|l|}{ Chest X-Ray, No. (\%) } \\
\hline Normal & $36(72)$ & & & & \\
\hline Opacity & $14(28)$ & & & & \\
\hline
\end{tabular}

${ }^{\mathrm{a}}$ In g/dL unit, hemoglobin values were $15.74 \pm 3.39$ (range10.8-32).

${ }^{\mathrm{b}} \mathrm{P}$ value shows statistical significance since it is lower than 0.05 .

found a positive association between a lower Apgar score and a higher prevalence of sepsis, but our study did not include that data.

Vitamin D Receptors are widely expressed in immune system cells and epithelial tissues (23). Vitamin D, especially its active metabolite 1,25 dihydroxyvitamin D3, plays an important role in calcium hemostasis and immune system activity (25). Demand for calcium increases during the last trimester of pregnancy, such that about 30 grams of calcium is removed from maternal skeleton by the hormonal effects to make the neonatal skeleton. Thus, receiving vitamin D and calcium is important during pregnancy for fetal hemostasis, bone growth, and mineralization $(26,27)$. There is still no agreement regarding the optimum level of vitamin D in pregnancy and in neonates, but 11 nanograms per milliliter $(\mathrm{ng} / \mathrm{mL})$ in the neonate's serum prevents rickets, and serum level above $30 \mathrm{ng} / \mathrm{mL}$ is needed to prevent secondary hyperthyroidism and increase in calcium absorption. Thus, above $30 \mathrm{ng} / \mathrm{mL}$ is ideal and below $20 \mathrm{ng} / \mathrm{mL}$ shows deficiency $(28,29)$. Other studies evaluated if low vitamin D levels may cause intrauterine growth retardation, low birth weight, or EOS. Sufficient maternal vitamin D levels may boost maternal and neonatal immune systems (30-32). Supplemental vitamin D during pregnancy may help reduce the occurrence of EOS in term neonates $(18,33)$.

Our study limitations included the limited sample size that may highlight differences between groups' averages. In our relatively small sample, we did not have the option to find the exact matching criteria for GA, and consequently, birth weight. Hence, we matched the neonates based on a GA range rather than an exact number. A larger sample size may make finding the exact matching pairs achievable to better identify the possible association between the serum vitamin D levels in neonates and their mothers for both case and control groups. Also, data stratification based on possible confounding variables, such as birth weight, GA, and route of delivery, in a larger study may better identify the strength of the association of serum vitamin D level with the prevalence of EOS. We were not able to match the case and controls for maternal vitamin D supplement consumption since that data was not recorded. Future research needs to address this factor and control for supplement consumption.

\subsection{Conclusion}

Development of EOS may be associated with vitamin D deficiency in maternal and neonatal serum. Neonates who developed EOS also had a lower birth weight and higher chance of being delivered through C-section. For healthy 


\begin{tabular}{|c|c|c|c|}
\hline Maternal Information & Sepsis Cases, $(n=44)$ & Control Group $(n=46)$ & P Value \\
\hline C-Section, No. (\%) & $34(77.3)$ & $19(41.3)$ & $0.001^{\mathrm{b}}$ \\
\hline Vaginal Delivery, No. (\%) & $10(22.7)$ & $27(58.7)$ & $0.00052^{\mathrm{b}}$ \\
\hline \multicolumn{4}{|l|}{ Gravid, No. (\%) } \\
\hline 1 & $16(36.4)$ & $27(58.7)$ & $0.034^{\mathrm{b}}$ \\
\hline 2 & $22(50.0)$ & $15(32.6)$ & 0.0927 \\
\hline 3 & $6(13.6)$ & $4(8.7)$ & 0.4533 \\
\hline Maternal BMI $\left(\mathbf{K g} / \mathbf{M}^{2}\right)$ & & & 0.087 \\
\hline Mean \pm SD & $28.41 \pm 1.71$ & $27.8 \pm 1.61$ & \\
\hline Range & $24-32$ & $25-32$ & \\
\hline Maternal Age (year) & & & 0.193 \\
\hline Mean $\pm S D$ & $31.07 \pm 6.09$ & $29.59 \pm 4.56$ & \\
\hline Range & $19-51$ & $22-45$ & \\
\hline PMH Negative, No. (\%) & $28(63.6)$ & $32(69.6)$ & 0.704 \\
\hline IVF, No. (\%) & $4(9.1)$ & $3(6.5)$ & 0.6527 \\
\hline Gestational Diabetes Mellites, No. (\%) & $9(20.5)$ & $6(13.0)$ & 0.3472 \\
\hline Hypothyroidism, No. (\%) & $3(6.8)$ & $5(10.9)$ & 0.4965 \\
\hline Vitamin D in Maternal Serum (nmol/L) & & & $0.005^{\mathrm{b}}$ \\
\hline Mean $\pm S D$ & $55.01 \pm 22.11$ & $68.24 \pm 21.22$ & \\
\hline Range & 13.48-157.75 & 23.96-124.8 & \\
\hline
\end{tabular}

Abbreviations: BMI, Body mass index; SD, Standard deviation; IVF, In vitro fertilization; PMH, Past medical history.

${ }^{\mathrm{a}} \mathrm{T}$-test showed that mothers in the control group had higher vitamin D levels in serum.

${ }^{\mathrm{b}} \mathrm{P}$ value shows there is statistical significance since it is lower than 0.05 .

Table 4. Correlations Between Vitamin D Levels in the Serum of Mothers and Their Neonates ${ }^{\mathrm{a}}$

\begin{tabular}{|c|c|c|}
\hline Maternal Serum Vitamin D Level & $\mathbf{R}$ & P Value \\
\hline Sepsis Cases Serum Vitamin D Level & 0.241 & 0.115 \\
\hline Control Group Serum Vitamin D Level & 0.731 & $<0.001^{\mathrm{b}}$ \\
\hline
\end{tabular}

neonates, there was a positive correlation between serum vitamin D levels in mothers and their neonates. Future studies may need to evaluate the effects of taking vitamin D supplements by pregnant women who have vitamin D deficiency on the incidence of EOS.

\section{Acknowledgments}

We wish to thank the mothers and their neonates for participation in this study and the NICU staff at Taleghani Hospital, affiliated to Shahid-Beheshti University of Medical Sciences, for making this study possible.

\section{Footnotes}

Authors' Contribution: Study concept and design: A. N., and A. S.; analysis and interpretation of data: A. N., and H. G.; drafting of the manuscript: H. G; critical revision of the manuscript for important intellectual content: A. N., H. G., and A. S.; statistical analysis: H. G.. administrative, technical, and material support, study supervision: A. N.

Conflict of Interests: The authors have no conflicts of interest to declare.

Data Reproducibility: Tihe data presented in this study are openly available in one of the repositories or will be available on request from the corresponding author by this journal representative at any time during submission or after publication. Otherwise, all consequences of possible withdrawal or future retraction will be with the corresponding author.

Ethical Approval: Patient privacy and medical research ethics were observed. IR.SBMU.MSP.REC.1398.687.

Funding/Support: This study received no funding. Informed Consent: Signed written informed consent was obtained from mothers of the neonates. 


\section{References}

1. Misra M, Pacaud D, Petryk A, Collett-Solberg PF, Kappy M; Drug, et al. Vitamin D deficiency in children and its management: review of current knowledge and recommendations. Pediatrics. 2008;122(2):398417. doi: 10.1542/peds.2007-1894. [PubMed: 18676559].

2. Mulligan ML, Felton SK, Riek AE, Bernal-Mizrachi C. Implications of vitamin D deficiency in pregnancy and lactation. Am J Obstet Gynecol. 2010;202(5):429 e1-9. doi:10.1016/j.ajog.2009.09.002. [PubMed: 19846050]. [PubMed Central: PMC3540805].

3. Wang TT, Nestel FP, Bourdeau V, Nagai Y, Wang Q, Liao J, et al. Cutting edge: 1,25-dihydroxyvitamin D3 is a direct inducer of antimicrobial peptide gene expression. J Immunol. 2004;173(5):2909-12. doi: 10.4049/jimmunol.173.5.2909. [PubMed: 15322146].

4. Kempker JA, Tangpricha V, Ziegler TR, Martin GS. Vitamin D in sepsis: from basic science to clinical impact. Crit Care. 2012;16(4):316. doi: 10.1186/cc11252. [PubMed: 22809263]. [PubMed Central: PMC3580673].

5. Hatun S, Ozkan B, Bereket A. Vitamin D deficiency and prevention: Turkish experience. Acta Paediatr. 2011;100(9):1195-9. doi: 10.1111/j.16512227.2011.02383.x. [PubMed: 21672012].

6. Naseh A, Ashrafzadeh S, Rassi S. Prevalence of vitamin D deficiency in pregnant mothers in Tehran and investigating its association with serum glucose and insulin. J Matern Fetal Neonatal Med. 2018;31(17):2312-8. doi: 10.1080/14767058.2017.1342796. [PubMed: 28662591].

7. Aranow C. Vitamin D and the immune system. J Investig Med. 2011;59(6):881-6. doi: 10.2310/JIM.0b013e31821b8755. [PubMed: 21527855]. [PubMed Central: PMC3166406].

8. Clancy N, Onwuneme C, Carroll A, McCarthy R, McKenna MJ, Murphy N, et al. Vitamin D and neonatal immune function.J Matern Fetal Neonatal Med. 2013;26(7):639-46. doi: 10.3109/14767058.2012.746304. [PubMed: 23131172].

9. Yang LR, Li H, Yang TY, Zhang T, Zhao RC. [Relationship between vitamin D deficiency and early-onset neonatal sepsis]. Zhongguo Dang Dai Er Ke Za Zhi. 2016;18(9):791-5. [PubMed: 27655531]. [PubMed Central: PMC7389977].

10. Cione E, Lucente M, Gallelli L, De Sarro G, Luciani F, Cristina Caroleo M. Innate Immunity and Human Milk MicroRNAs Content: A New Perspective for Premature Newborns. J Compr Ped. 2017;In press(In press). doi: 10.5812/compreped.43359.

11. Esposito S, Lelii M. Vitamin D and respiratory tract infections in childhood. BMC Infect Dis. 2015;15:487. doi: 10.1186/s12879-015-1196-1. [PubMed: 26521023]. [PubMed Central: PMC4628332].

12. Dessì A, Pravettoni C, Ottonello G, Birocchi F, Cioglia F, Fanos V. Neonatal sepsis. J Pediatr Neonatal Individ Med. 2014;3(2):e030273.

13. Naseh A, Taslimi-Taleghani N. Risk factors associated with serious bacterial infections among newborns with high body temperature. J Prev Med Hyg. 2020;61(4):E556-62. doi: 10.15167/24214248/jpmh2020.61.4.1461. [PubMed: 33628961]. [PubMed Central: PMC7888388].

14. Black RE, Cousens S, Johnson HL, Lawn JE, Rudan I, Bassani DG, et al. Global, regional, and national causes of child mortality in 2008: a systematic analysis. Lancet. 2010;375(9730):1969-87. doi: 10.1016/S01406736(10)60549-1. [PubMed: 20466419].

15. Workneh Bitew Z, Worku T, Alemu A. Effects of vitamin D on neonatal sepsis: A systematic review and meta-analysis. Food Sci Nutr. 2021;9(1):375-88. doi: 10.1002/fsn3.2003. [PubMed: 33473300]. [PubMed Central: PMC7802542].

16. Simonsen KA, Anderson-Berry AL, Delair SF, Davies HD. Earlyonset neonatal sepsis. Clin Microbiol Rev. 2014;27(1):21-47. doi: 10.1128/CMR.00031-13. [PubMed: 24396135]. [PubMed Central: PMC3910904].

17. Haslam DB. Epidemiology of Infections. In: Behrman RE, Vaughan III VC, editors. Nelson textbook of pediatrics. Elsevier; 2020.1000 p.
18. Cetinkaya M, Cekmez F, Buyukkale G, Erener-Ercan T, Demir F, Tunc $\mathrm{T}$, et al. Lower vitamin D levels are associated with increased risk of early-onset neonatal sepsis in term infants. J Perinatol. 2015;35(1):3945. doi: 10.1038/jp.2014.146. [PubMed: 25102323].

19. Kanth S, Reddy K, Abhishek G. Association between vitamin D levels and early onset sepsis in infants: a prospective observational study. Int J Contemp Pediatrics. 2016:1189-92. doi: 10.18203/23493291.ijcp20163168.

20. Say B, Uras N, Sahin S, Degirmencioglu H, Oguz SS, Canpolat FE. Effects of cord blood vitamin D levels on the risk of neonatal sepsis in premature infants. Korean J Pediatr. 2017;60(8):248-53. doi: 10.3345/kjp.2017.60.8.248. [PubMed: 29042866]. [PubMed Central: PMC5638722].

21. Dhandai R, Jajoo M, Singh A, Mandal A, Jain R. Association of vitamin D deficiency with an increased risk of late-onset neonatal sepsis. Paediatr Int Child Health. 2018;38(3):193-7. doi: 10.1080/20469047.2018.1477388. [PubMed: 30003852].

22. Agrawal A, Gupta A, Shrivastava J. Role of Vitamin-D Deficiency in Term Neonates with Late-Onset Sepsis: A Case-Control Study. J Trop Pediatr. 2019;65(6):609-16. doi: 10.1093/tropej/fmz021. [PubMed: 31006010].

23. Ozdemir AA, Cag Y. Neonatal Vitamin D status and the risk of neonatal sepsis. PakJ Med Sci. 2019;35(2):420-5. doi: 10.12669/pjms.35.2.342. [PubMed: 31086526]. [PubMed Central: PMC6500822].

24. Saboute M, Yavar R, Kashaki M, Khaledi FK, Khalesi N, Rohani F. Investigation of association between maternal 25-OH vitamin D serum levels and neonatal early onset sepsis in newborns by evaluating key factors. Lipids Health Dis. 2019;18(1):153. doi: 10.1186/s12944-019-1095-3. [PubMed: 31299987]. [PubMed Central: PMC6626329].

25. Di Rosa M, Malaguarnera M, Nicoletti F, Malaguarnera L. Vitamin D3: a helpful immuno-modulator. Immunology. 2011;134(2):123-39. doi: 10.1111/j.1365-2567.2011.03482.x. [PubMed: 21896008]. [PubMed Central: PMC3194221].

26. Kovacs CS. Calcium and bone metabolism in pregnancy and lactation. J Clin Endocrinol Metab. 2001;86(6):2344-8. doi: 10.1210/jcem.86.6.7575. [PubMed: 11397820].

27. Cavalier E, Delanaye P, Morreale A, Carlisi A, Mourad I, Chapelle JP, et al. [Vitamin D deficiency in recently pregnant women]. Rev Med Liege. 2008;63(2):87-91. [PubMed: 18372546].

28. Holick MF, Binkley NC, Bischoff-Ferrari HA, Gordon CM, Hanley DA, Heaney RP, et al. Evaluation, treatment, and prevention of vitamin D deficiency: an Endocrine Society clinical practice guideline. J Clin Endocrinol Metab. 2011;96(7):1911-30. doi: 10.1210/jc.2011-0385. [PubMed: 21646368].

29. Marshall I, Mehta R, Petrova A. Vitamin D in the maternal-fetalneonatal interface: clinical implications and requirements for supplementation. J Matern Fetal Neonatal Med. 2013;26(7):633-8. doi: 10.3109/14767058.2012.746306. [PubMed: 23131182].

30. Viljakainen HT, Saarnio E, Hytinantti T, Miettinen M, Surcel H, Makitie $\mathrm{O}$, et al. Maternal vitamin D status determines bone variables in the newborn. J Clin Endocrinol Metab. 2010;95(4):1749-57. doi: 10.1210/jc.2009-1391. [PubMed: 20139235].

31. McCarthy R, McCallion N, Harrison G, Molloy EJ. Relationship between vitamin D and alkaline phosphatase in very-low-birthweight infants. Arch Dis Child Fetal Neonatal Ed. 2009;94(1):F77-8. doi: 10.1136/adc.2008.146522. [PubMed: 19103781].

32. Soheilykhah S, Mojibian M, Rashidi M, Rahimi-Saghand S, Jafari F. Maternal vitamin D status in gestational diabetes mellitus. Nutr Clin Pract. 2010;25(5):524-7. doi: 10.1177/0884533610379851. [PubMed: 20962313].

33. De Ronne N, De Schepper J, Societe flamande de P. [Recommendations for vitamin D supplementation in infants and young children]. J Pharm Belg. 2013;(3):12-21. [PubMed: 24804408]. 